\title{
Hành trình của nghiên cứu về quá trình xử lý thông tin 3D đa lọc
}

\author{
Nguyễn Minh Hoàng \\ Đại học Châu Á Thái Bình Dương Ritsumeikan \\ Beppu, Oita 874-8577, Nhật Bản \\ 05 tháng 012022

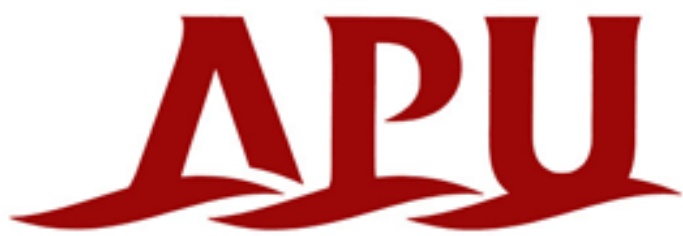 \\ Ritsumeikan Asia Pacific University
}

Nghiên cứu có tính chất lý thuyết cơ sở được gọi tên là "3D information process", hay như nhóm nghiên cứu sau này thường gọi ngắn gọn hơn là "3D process" được phát triển trong giai đoạn 2011-2012. Bản thảo nghiên cứu đầu tiên được hoàn thành năm 2012, ở trạng thái working paper, hiện vẫn có thể truy cập tại IDEAS RePEc repository của Trung tâm CEB, Université Libre de Bruxelles (WP No. 12-036): https://econpapers.repec.org/RePEc:sol:wpaper:2013/134797.

Sau đó bản thảo nói trên được nộp cho tạp chí học thuật International Journal of Transitions and Innovation Systems, của Inderscience, và được gửi đi bình duyệt. Tuy vậy, phải tới cuối năm 2014, bài nghiên cứu nói trên mới được xuất bản sau vài vòng phản biện, chỉnh sửa. Lúc này, tiêu đề nghiên cứu xuất bản chính thức [1] đã thay đổi một chút so với bản thảo WP nói trên. Bài xuất bản truy cập tại địa chỉ: https://www.inderscienceonline.com/doi/pdf/10.1504/IJTIS.2014.068306.

Như vậy, tính đến nay nghiên cứu này đã có mặt trong hệ thống thông tin học thuật được 10 năm. Trong khoảng thời gian này, từ một lý thuyết mới mẻ mô phỏng quá trình tương tự cơ chế hoạt động của phin cà-phê quen thuộc ở Việt Nam, nó đã dần trở nên phổ biến hơn qua các ứng dụng và dẫn chiếu của các tác giả quốc tế trong địa hạt quản trị, tâm lý, hệ thống thông tin, đổi mới sáng tạo, giáo dục, v.v.. [2-13]. 


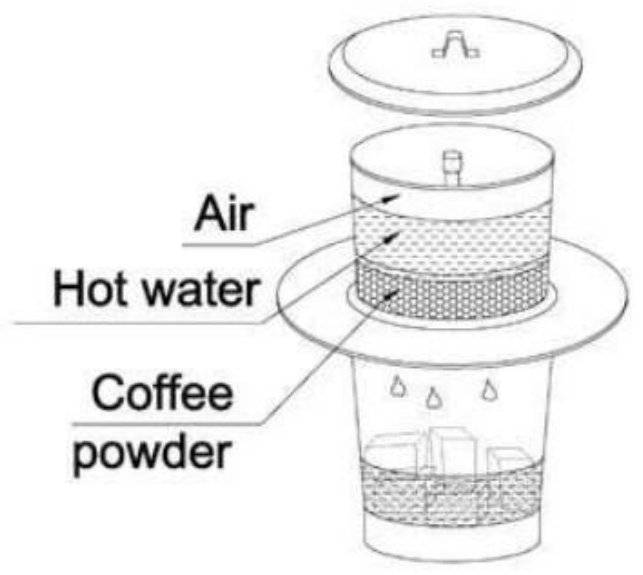

Hình trích từ WP No. 12-036

Nghiên cứu "3D process" giới thiệu một trong số ba lý thuyết thường xuyên tương tác qua lại, tạo thành một hệ thống, gọi là "serendipity-mindsponge-3D" (SM3D) [1,14-16]. Hệ thống SM3D khi kết hợp với nhau, và sử dụng tiếp cận thống kê lưới Bayesian giúp giải thích nhiều hiện tượng tâm lý-xã hội một cách hiệu quả, chẳng hạn "cộng tính văn hóa" [17] hay "tiếp biến văn hóa" [18].

Thường thường, các lý thuyết tâm lý xã hội thường cần rất nhiều thời gian, hàng nhiều thập niên, để học giới có thể tìm kiếm bằng chứng hoặc kiểm tra tính vững chắc của hệ thống logic lập luận. Xét một cách tương đối, 3D nói riêng và hệ thống SM3D nói chung được coi là còn rất mới. Tuy vậy, những ứng dụng và bằng chứng ban đầu phần nào cho thây hiệu quả khá rõ nét và có tính chất khích lệ.

\section{References}

[1] Vuong, Q. H., \& Napier, N. K. (2014). Making creativity: the value of multiple filters in the innovation process. International Journal of Transitions and Innovation Systems, 3(4), 294-327.

[2] Alalshiekh, A. (2018). The impact of inward FDI on the management of human capital development in developing countries: Lessons from Saudi Arabia (Doctoral dissertation, Brunel University London).

[3] de la Garza Carranza, M. T., Guzmán-Soria, E., López-Lemus, J. A., \& Martínez, A. C. S. (2020). Social entrepreneurship innovation: A study from Mexico. Entrepreneurial Business and Economics Review, 8(4), 201-220.

[4] Gondim, S. M. G., Techio, E. M., Loiola, E., Carias, I. A., Colman, K., Silva, B., \& Malhado, L. (2019). Creatividad, innovación y características de la tarea de junior empresas: estudios de casos múltiples. Revista Psicologia Organizações $e$ Trabalho, 19(4), 762-771. 
[5] Indriartiningtias, R., \& Hartono, B. (2017, December). Creativity in organization: A literature review. In: 2017 IEEE International Conference on Industrial Engineering and Engineering Management (pp. 1787-1791). IEEE.

[6] Kowalski, A. M., \& Rybacki, J. (2021). Moderate Innovator Trap-Does the Convergence of Innovation Performance Occur in the World Economy?. Economies, 9(1), 11.

[7] Liu, L., Wan, W., \& Fan, Q. (2021). How and When Telework Improves Job Performance During COVID-19? Job Crafting as Mediator and Performance Goal Orientation as Moderator. Psychology Research and Behavior Management, 14, 2181-2195.

[8] Sugiman, S., Suyitno, A., Pujiastuti, E., Masrukan, M., \& Hidayah, I. (2021, February). Penguatan Pembelajaran dan Penilaian yang Bermuatan 4C Competence in Mathematics di Era "Merdeka Belajar" pada Guru-guru SMPN 24 Semarang. In: PRISMA, Prosiding Seminar Nasional Matematika (Vol. 4, pp. 487492).

[9] Suyito, A. (2020). Analisis hasil studi nasional dan internasional. BAHAN AJAR PERKULIAHAN, 2020(2).

[10] Suyitno, A. (2020, June). Growth of student mathematical creativity as part of 4C competence for entering the 21st century. Journal of Physics: Conference Series, 1567(2), 022100.

[11] Suyitno, A., Suyitno, H., \& Sugiharti, E. (2021, June). Integration of 4C competencies in online mathematics learning in junior high schools during the covid-19 pandemic. In: Journal of Physics: Conference Series, 1918(4), 042083.

[12] 陳思貽. (2016). 雲端行動學習與創意環境對創意表現的影響. National Taiwan Normal Univ. http://rportal.lib.ntnu.edu.tw/handle/20.500.12235/96663

[13] 蔡依帆. (2014). 雲端行動學習對大學生學習動機及創意表現之影響-以電腦影像處理 課 程 為 例 . National Taiwan Normal Univ. http://rportal.lib.ntnu.edu.tw/handle/20.500.12235/96364

[14] Napier, N. K., \& Vuong, Q. H. (2013). Serendipity as a strategic advantage?. In: T. Wilkinson (ed.) Strategic Management in the 21st Century (pp. 175-199). Westport, CT: ABC-Clio.

[15] Vuong, Q. H. (2016). Global mindset as the integration of emerging socio-cultural values through mindsponge processes: A transition economy perspective. In: J. Kuada (ed.) Global Mindsets: Exploration and Perspectives (pp. 109-126). London: Routledge.

[16] Vuong, Q. H., \& Napier, N. K. (2015). Acculturation and global mindsponge: an emerging market perspective. International Journal of Intercultural Relations, 49, 354-367.

[17] Vuong, Q. H., et al. (2018). Cultural additivity: behavioural insights from the interaction of Confucianism, Buddhism and Taoism in folktales. Palgrave Communications, 4(1), 143.

[18] Vuong, Q. H., et al. (2019). Cultural evolution in Vietnam's early 20th century: A Bayesian networks analysis of Hanoi Franco-Chinese house designs. Social Sciences \& Humanities Open, 1(1), 100001. 